ISAHP2016, London, U.K. - Pereyra-Rojas \& Mu: Measuring Scholarship Identity

Congruence.

\title{
MEASURING SCHOLARSHIP IDENTITY CONGRUENCE IN HIGHER EDUCATION INSTITUTIONS: A MULTICRITERIA APPROACH
}

\author{
Milagros Pereyra-Rojas \\ University of Pittsburgh \\ Milagros@pitt.edu \\ Enrique $\mathrm{Mu}$ \\ Carlow University \\ University of Pittsburgh \\ emu@,carlow.edu \\ enriquem@pitt.edu
}

\begin{abstract}
Faculty scholarship preferences, such as scholarship of discovery, application, integration, teaching and engagement constitute a set of values, rather a source of scholarship identity for academics. However, Higher-Ed Institutions have their own expectations in terms of what type of scholarship should be given priority. Finally, environmental circumstances (e.g. accreditation efforts, faculty turnover, institutional consulting contracts) lead faculty to focus their work in areas (e.g. teaching) that may not be congruent either with faculty or institutions' priorities. Research suggests that when there is congruence in the priority given to the different types of scholarship as well as in the actual work focus, there will be higher faculty productivity and job satisfaction. Therefore, it is important to measure the priority that faculty and institutions give to the different types of scholarship. This paper proposes a multi-criteria approach, based on the Analytic Hierarchy Process, and reports on a pilot conducted for this purpose.
\end{abstract}

Keywords: scholarship identity, scholarship types, scholarship preferences.

\section{Introduction}

Recent studies suggest that the scholar's identification with specific Boyer's scholarship dimensions, as well as how congruent it is with institutional expectations and the scholar's actual academic work focus, contribute to academic productivity and faculty job satisfaction (Pereyra-Rojas, 2014). 


\section{Literature Review}

The encompassing theory for this study has been developed by Pereyra-Rojas (2014) and a paper based on this is currently under first round of review in Higher Education journal. The original idea for this study came up from the findings of a qualitative investigation (Mu and Pereyra-Rojas, 2015). Also, this study builds up on the academic stream of research related to Boyer (1990) and Van de Ven (2007)'s scholarship types.

\section{Hypotheses/Objectives}

This pilot study proposes a way to apply the theoretical concept of congruence of scholarship identity, institutional expectations and academic work focus. It uses AHP to elicit faculty and institutional scholarship expectations and suggests ways in which these results could be used.

\section{Research Design/Methodology}

Using Pereyra-Rojas (2014)'s theory of academic alignment as the contextual theoretical framework, this study will use AHP questionnaires to survey academic faculty and officers to prioritize their respective scholarship identity and expectations and measure the presence of academic alignment gaps.

\section{Data/Model Analysis}

The proposed AHP model to prioritize faculty scholarship identity, institutional expectations and academic work focus is constituted by a two-level hierarchy. The Goal is Prioritization of Scholarship Dimensions and the second level is constituted by the five scholarship dimensions: Discovery, Application, Integration, Teaching and Integration.

\section{Limitations}

This study constitutes a pilot to explore how a full-blown scholarship identity analysis could take place and has the limitations inherent to any pilot study.

\section{Conclusions}

Measuring the extent of academic congruence among faculty scholarship identity, institutional expectations and academic work focus is important to increase faculty productivity and job satisfaction. This study operationalizes theoretical findings into a multi-criteria based approach to use it effectively in higher-education settings. you have the opportunity to share with the world your contributions. What can you conclude from this study? What are your theoretical and/or practical contributions? How can you be certain of your achievements (e.g. is the model being used?) What are the next studies you would propose in this line of scholarship? How does your contribution fit or differs International Symposium of 
ISAHP Article: A Style Guide for Paper Proposals To Be Submitted to the International Symposium of the Analytic Hierarchy Process 2016, London, U.K.

into (or from) the current stream of scholarship. Make sure that your conclusions are based on the current study and that clearly show an important contribution to the theory and/or practice of AHP/ANP.

\section{Key References}

Boyer, E. L. (1990). Scholarship Reconsidered: Priorities of the Professoriate. In (pp. 1525): The Carnegie Foundation for the Advancement of Teaching.

Pereyra-Rojas, M. (2014). A Theoretical, Empirical and Practical Approach to Academic Knowledge Production and Job Satisfaction: The Role of Academic Alignment Unpublished Doctoral Dissertation. Case Western Reserve University,

Pereyra-Rojas, M., \& Mu, E. (2015). Impact on Society versus Impact on Knowledge: Why Latin American Scholars do not Participate in Latin American Studies. Latin American Research Review, 50, 2.

Van de Ven, A. H. (2007). Engaged Scholarship: A Guide for Organizational and Social Research. Great Britain: Oxford University Press.

\section{Appendix}

It is also possible to apply our analysis to individual faculty as shown below for selfreflecting purposes. In this example, the faculty member would prioritize the degree of identification and the extent of academic work with each dimension, using AHP pairwise comparison. The prioritization of institutional expectations could be obtained from academic officers or it could be also provided by the individual faculty using pairwise comparison and perceived institutional expectations. Figure 1 below shows that this particular faculty member identifies with different forms of scholarship. Interestingly, scholarship of discovery is the dimension with which this scholar identifies the least; however it is the dimension which the institution values by far the most.

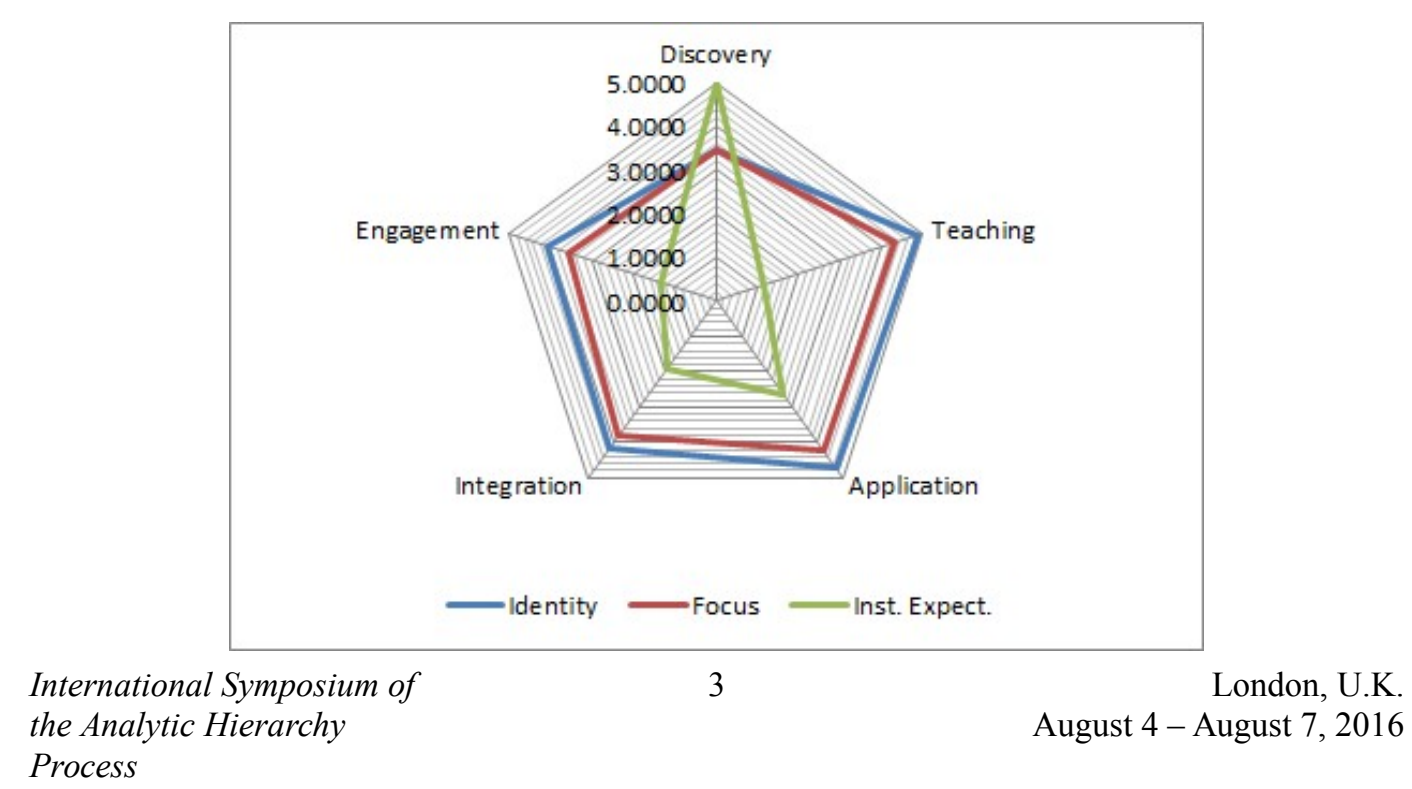


ISAHP Article: A Style Guide for Paper Proposals To Be Submitted to the International Symposium of the Analytic Hierarchy Process 2016, London, U.K.

\section{Figure 1 - Faculty Individual Analysis}

